\title{
Optimization of process variables on flexural properties of epoxy/organo-montmorillonite nanocomposite by response surface methodology
}

\author{
W. S. Chow*, Y. P. Yap \\ School of Materials and Mineral Resources Engineering, Engineering Campus, Universiti Sains Malaysia, \\ Nibong Tebal 14300 Pulau Pinang, Malaysia
}

\begin{abstract}
This study attempted to investigate the preparation and optimization of the flexural properties for epoxy/organomontmorillonite (OMMT) nanocomposites. In-situ polymerization method was used to prepare epoxy/OMMT nanocomposites. The diglycidyl ether bisphenol A (DGEBA) and curing agent were mixed first, followed by the addition of OMMT. In this study, computer aided statistical methods of experimental design (Response Surface Methodology, RSM) was used to investigate the process variables on the flexural properties of epoxy/4wt\% OMMT nanocomposites. Speed of mechanical stirrer, post-curing time and post-curing temperature were chosen as process variables in the experimental design. Results showed that the speed of mechanical stirrer, post-curing time and post-curing temperature were able to influence the flexural modulus and flexural yield stress of epoxy/4 wt \% OMMT nanocomposites. The results of optimization showed that the design of experiment (DOE) has six combination of operating variables which have been obtained in order to attain the greatest overall desirability.
\end{abstract}

Keywords: polymer composites, nanocomposites, materials testing, response surface methodology, design of experiment

\section{Introduction}

Polymer nanocomposites have received considerable attention and great interest in industry and academia. Epoxy resin systems are increasingly used as matrices in composite materials for a widespread application such as automotive, aerospace, structural application, shipbuilding and electronic devices owing to their high strength, low viscosity, low shrinkage during curing, low creep and good adhesion to many substrates $[1,2]$. Among the epoxy-inorganic nanocomposites, in particularly, the use of layered silicate is due to the fact that clay has high aspect ratio, plate morphology, natural availability and low cost [3]. Modification of montmorillonite surface may reduce the physical or electrostatic bonding force of clay interlayer, which leads to favor the formation of nanocomposites and to exfoliate the interlayer of the silicate layers. However, the organo-montmorillonite is relatively expensive. Montmorillonite is classified as magnesium aluminum silicate which has sheet morphology, and can be used to make a new class of polymer/clay nanocomposites [4].

In-situ polymerization has been explored to produce thermosets nanocomposites. This method has been extensively used for the production of both intercalated and exfoliated epoxy-based nanocomposites [5]. In this method, the modified layered silicate is swollen by a liquid monomer or a monomer solution. The monomer migrates into galleries of the layered silicate, so that the polymerization can occur within the intercalated sheets. The polymer-

*Corresponding author, e-mail: shyang@eng.usm.my

(c) BME-PT and GTE 
ization reaction can be carried out by heat, radiation or a suitable initiator [6]. The formation and morphology of epoxy-clay nanocomposites is determined by a balance between the intragallery and the extragallery polymerization rate of monomer or prepolymer in the clay layers [7].

Strategy of experimentation is a general method to planning and conducting the experiment. Usually, experiments are performed to generate data from the process and then use the information from the experiment to establish new conjectures which lead to new experiments, and so on [8]. In engineering, experimentation plays an important role in new product design, manufacturing process development, and process improvement. The objective in many cases may be to develop a robust process, that is, a process affected minimally by external sources of variability [8].

Design of experiment (DOE) is a structured, organized method that is used to determine the relationship between the different factors $\left(x_{s}\right)$ affecting a process and the output of the process (y) [9]. Design of experiments includes designing a set of ten or more experiments, in which all relevant factors are varied systematically. DOE uses the smallest possible number of experimental runs to discover and find the optimum settings for the process [9]. DOE provides a cost-effective means for solving problems and developing new processes. The simplest, but most powerful, DOE tool is two-level factorial design, where each input variable is varied at high (+) and low (-) levels and the output observed for resultant changes. Statistics can then help to determine which inputs have the greatest effect on outputs [10]. Another advantage of DOE is that it shows how interconnected factors respond over a wide range of values, without requiring the testing of all possible values directly. DOE fits response data to mathematical equations. Collectively, these equations serve as models to predict what will happen for any given combination of values. With these models, it is possible to optimize critical responses and find the best combination of values [11].

Response surface methodology (RSM) has been widely used in the empirical study of the relationship between one or more measured responses such as yield, on one hand, and a number of input variables such as time, temperature, pressure, and con- centration on the other hand [12]. RSM is a collection of mathematical and statistical techniques that are useful for the modeling and analysis of problems in which a response of interest is influenced by several variables and the response surface can be explored to determine important characteristics such as optimum operating conditions. In our previous studies, it was found that $4 \mathrm{wt} \%$ of OMMT could achieve a balance of flexural modulus, strength and strain. In this study, Response Surface Methodology was used to investigate the effects of processing variables on the flexural properties of epoxy/OMMT nanocomposites. The 3 factors include: (i) mechanical stirrer speed, (ii) post-curing time, and (iii) post-curing temperature. Suitable combination of optimization for flexural properties of epoxy/OMMT nanocomposites will be determined.

\section{Materials and methods}

\subsection{Materials}

The epoxy resin used as the polymer matrix was DER 331, a bisphenol A diglycidyl ether-based resin (DGEBA) supplied by Dow Chemical. This epoxy resin offered epoxide equivalent weight of $182-192$, viscosity of $11000-14000 \mathrm{mPa} \cdot \mathrm{s}$, and density of $1.16 \mathrm{~g} / \mathrm{cm}^{3}$ at $25^{\circ} \mathrm{C}$. The cycloaliphatic amine is a phenol free version and was used as curing agent for the epoxy resin DGEBA system. The cycloaliphatic amine (HY 2964) was supplied by Ciba-Geigy. The viscosity of HY 2964 is $30-70 \mathrm{cP}$ while the density of the resin is $8.3 \mathrm{Ib} / \mathrm{gal}$. The organo-montmorillonite (OMMT) (Nanomer 1.28E) is an organosilicate modified by quaternary trimethylstearylammonium ions having an approximate aspect ratio of 75-120, was purchased from Nanocor Co., USA.

\subsection{Preparation and characterization of epoxy/OMMT nanocomposites}

The DGEBA and curing agent were mixed first, followed by the addition of OMMT. The mixing of the DGEBA, curing agent and OMMT was performed using mechanical stirrer. Then, the mixture was poured into a square plastic mould with dimension $13 \mathrm{~cm} \times 13 \mathrm{~cm} \times 8 \mathrm{~cm}$ (length $\times$ width $\times$ height) and degassed using a vacuum oven. Fur- 
ther, curing of epoxy/OMMT nanocomposites was carried out at room temperature for 1 hour and followed by post-curing. The flexural properties of the epoxy/OMMT nanocomposites were determined according to the ASTM D790 using an Instron 3366 machine. The dimension of the sample are $110 \mathrm{~mm} \times 12.7 \mathrm{~mm} \times 3 \mathrm{~mm}$ (length $\times$ width $\times$ thickness). The span length was set at $50 \mathrm{~mm}$ and the testing speed was set at $5 \mathrm{~mm} / \mathrm{min}$. The flexural modulus and flexural yield stress were determined.

\subsection{Experimental Design- Response Surface Methodology (RSM)}

\subsubsection{Study on the effects of processing variables}

In this study, the effect of three independent variables in the nanocomposites system can be investigated by using rotatable central composite design (CCD), which is one of the designs in response surface methodology design. The three factors in the designs were considered. Factor $x_{1}$ is the mechanical stirrer speed, factor $x_{2}$ is the post-curing time

Table 1. Design matrix for central composite design

\begin{tabular}{|c|c|c|c|c|}
\hline & Number of runs & $\mathbf{X}_{1}$ & $\mathbf{X}_{2}$ & $\mathbf{X}_{3}$ \\
\hline 1 & \multirow{6}{*}{ Design center points } & 0 & 0 & 0 \\
\hline 2 & & 0 & 0 & 0 \\
\hline 3 & & 0 & 0 & 0 \\
\hline 4 & & 0 & 0 & 0 \\
\hline 5 & & 0 & 0 & 0 \\
\hline 6 & & 0 & 0 & 0 \\
\hline 7 & \multirow{6}{*}{ Axial or star point } & 1.68 & 0 & 0 \\
\hline 8 & & 0 & 0 & -1.68 \\
\hline 9 & & 0 & -1.68 & 0 \\
\hline 10 & & -1.68 & 0 & 0 \\
\hline 11 & & 0 & 1.68 & 0 \\
\hline 12 & & 0 & 0 & 1.68 \\
\hline 13 & \multirow{8}{*}{ Fractional factorial design } & 1 & -1 & 1 \\
\hline 14 & & 1 & 1 & 1 \\
\hline 15 & & 1 & 1 & -1 \\
\hline 16 & & -1 & 1 & -1 \\
\hline 17 & & -1 & -1 & 1 \\
\hline 18 & & -1 & 1 & 1 \\
\hline 19 & & -1 & -1 & -1 \\
\hline 20 & & 1 & -1 & -1 \\
\hline
\end{tabular}

and factor $x_{3}$ is the post-curing temperature. The measured responses $y$ is the flexural modulus and flexural yield stress of epoxy/OMMT nanocomposites. The experimental design matrix in coded variables employed in the present studies in nanocomposites systems were given in Table 1 . The various processing combination are furnished in coded variables in accordance with the usual practice of statistical design of experiments. The relationship between the coded and real variables is given in Table 2 . The results were analyzed by using Design Expert Version 6 software. Statistical analysis (regression and ANOVA analysis) of the responses are carried out to estimate the coefficients of the polynomial equation of the response by regression and to check the significance of the regression coefficients of independent variables and interaction variables by ANOVA. ANOVA is a method of testing for the equality of three or more population means by analyzing sample variances. Analysis of variance (ANOVA) table is used to determine the significance of the first degree, second degree, and cross-product terms of the polynomial. However, the ANOVA in this case confirms the adequacy of the quadratic model (the Model Probability $>F$ is less than 0.05).

\section{Results and discussion}

\subsection{Statistically designed experiments}

The experiment in the present study was conducted to determine the effect of process variables on the flexural properties of epoxy/OMMT nanocomposites. Approximately operating conditions for preparation of epoxy nanocomposites were required to be established for achieving the following objectives:

1. To minimize the curing time of epoxy nanocomposites.

2. To minimize the curing temperature used in the production of epoxy nanocomposites samples in order to maximize the final properties of the epoxy nanocomposites.

Table 2. Relationship between coded and real values

\begin{tabular}{|l|c|c|r|r|r|}
\hline \multirow{2}{*}{} & \multicolumn{5}{|c|}{ Coded levels/real levels } \\
\cline { 2 - 6 } & $\mathbf{- 1 . 6 8}$ & $\mathbf{- 1}$ & $\mathbf{0}$ & $\mathbf{1}$ & $\mathbf{1 . 6 8}$ \\
\hline Mechanical stirrer speed $[\mathrm{rpm}]$ & 528 & 800 & 1200 & 1600 & 1873 \\
\hline Post-curing time $[\mathrm{min}]$ & 36 & 50 & 70 & 90 & 104 \\
\hline Post-curing temperature $\left[{ }^{\circ} \mathrm{C}\right]$ & 93 & 100 & 110 & 120 & 127 \\
\hline
\end{tabular}


3. To determine the optimum processing condition of epoxy nanocomposites.

The achievements of the above objectives are subjected to the constraints and these constraints are necessary to impose during the optimization stage. Before attempting such optimization with constraint, basic functional relationship between the process variables and the following responses are to be clearly established:

1. Flexural yield stress of epoxy nanocomposites

2. Flexural modulus of epoxy nanocomposites

Since the efficacy of the process depends on the operating variables, the desired optimization cannot be accomplished by classical 'one variable at a time' approach, Response Surface Methodology (RSM) was adopted to determine the functional relationships between the process variables and ultimate performance characteristics of epoxy nanocomposites. In the case of the epoxy nanocomposites process, non-linear trends in the response are likely and hence a second order polynomial model could be considered to fit adequately the experimental results. Efficient classes of experimental designs known as Central Composite Design (CCD) are used to generate data that will be well suited for fitting a quadratic surface, which usually works well for process optimization. The basic central composite design consists of a $2^{k}$ factorial design for $k$ variables at two level $(-1,+1)$ superimposed on a star design with $2 k$ axial points and several replication at the central values.

Table 3 shows the experimental data for the effects of process variables on the flexural properties of epoxy/4 wt\% OMMT nanocomposites, i. e. flexural modulus and flexural yield stress. Process variables studies included speed of mechanical stirrer $\left(X_{1}\right)$, post curing time $\left(X_{2}\right)$ and post curing temperature $\left(X_{3}\right)$. Coded values and real values for each combination of process variables were given in Table 4 . The relation between the effects of process variables on flexural properties of epoxy/OMMT nanocomposites are discussed in this section.

Table 3. Effects of process variables on the flexural properties of epoxy/4 wt\% OMMT nanocomposites

\begin{tabular}{|c|c|c|c|c|c|c|c|c|}
\hline \multirow{3}{*}{ Std } & \multicolumn{6}{|c|}{ Combination of process variables } & \multirow{3}{*}{$\mathbf{a}$} & \multirow{3}{*}{ b } \\
\hline & \multicolumn{3}{|c|}{ Coded value } & \multicolumn{3}{|c|}{ Real value } & & \\
\hline & $\mathbf{X}_{1}$ & $\mathbf{X}_{2}$ & $\mathbf{X}_{3}$ & $\mathbf{X}_{1}$ & $\mathbf{X}_{2}$ & $\mathbf{X}_{3}$ & & \\
\hline 1 & -1 & -1 & -1 & 800 & 50 & 100 & 76 & 2853 \\
\hline 2 & 1 & -1 & -1 & 1600 & 50 & 100 & 70 & 2795 \\
\hline 3 & -1 & 1 & -1 & 800 & 90 & 100 & 79 & 2994 \\
\hline 4 & 1 & 1 & -1 & 1600 & 90 & 100 & 67 & 2581 \\
\hline 5 & -1 & -1 & 1 & 800 & 50 & 120 & 75 & 2900 \\
\hline 6 & 1 & -1 & 1 & 1600 & 50 & 120 & 71 & 2803 \\
\hline 7 & -1 & 1 & 1 & 800 & 90 & 120 & 80 & 3148 \\
\hline 8 & 1 & 1 & 1 & 1600 & 90 & 120 & 77 & 2937 \\
\hline 9 & -1.68 & 0 & 0 & 528 & 70 & 110 & 78 & 2925 \\
\hline 10 & 1.68 & 0 & 0 & 1873 & 70 & 110 & 73 & 2987 \\
\hline 11 & 0 & -1.68 & 0 & 1200 & 36 & 110 & 71 & 2914 \\
\hline 12 & 0 & 1.68 & 0 & 1200 & 104 & 100 & 79 & 3259 \\
\hline 13 & 0 & 0 & -1.68 & 1200 & 70 & 93 & 71 & 2652 \\
\hline 14 & 0 & 0 & 1.68 & 1200 & 70 & 127 & 88 & 3417 \\
\hline 15 & 0 & 0 & 0 & 1200 & 70 & 110 & 77 & 2873 \\
\hline 16 & 0 & 0 & 0 & 1200 & 70 & 110 & 77 & 2854 \\
\hline 17 & 0 & 0 & 0 & 1200 & 70 & 110 & 76 & 2928 \\
\hline 18 & 0 & 0 & 0 & 1200 & 70 & 110 & 76 & 2873 \\
\hline 19 & 0 & 0 & 0 & 1200 & 70 & 110 & 79 & 2723 \\
\hline 20 & 0 & 0 & 0 & 1200 & 70 & 110 & 78 & 2843 \\
\hline
\end{tabular}

$X_{1}$ : Speed of mechanical stirrer $[\mathrm{rpm}] ; X_{2}$ : Post curing time [minutes]; $X_{3}$ : Post curing temperature $\left[{ }^{\circ} \mathrm{C}\right]$;

$a$ : Response flexural yield stress [MPa]; $b$ : Response flexural modulus [MPa]

Table 4. The coded and real values of the 3 factorial levels in preparation process of epoxy/OMMT nanocomposites

\begin{tabular}{|l|c|c|c|c|c|c|}
\hline \multicolumn{1}{|c|}{ Name } & Symbol & Unit & Low actual & High actual & Low coded & High coded \\
\hline Speed of mechanical stirrer & $X_{1}$ & $\mathrm{rpm}$ & 528 & 1873 & -1.68 & 1.68 \\
\hline Post curing time & $X_{2}$ & $\mathrm{~min}$ & 36 & 104 & -1.68 & 1.68 \\
\hline Post curing temperature & $X_{3}$ & ${ }^{\circ} \mathrm{C}$ & 93 & 127 & -1.68 & 1.68 \\
\hline
\end{tabular}


Finally optimization of the overall process was considered taking into consideration of time and performance. The economic feasibility of the process depends on the time and temperature reduction of the epoxy/OMMT preparation process and desired mechanical properties of the end product. The optimization has to be performed by a well developed statistical method known as 'optimization with constraints'. This is a technique employed to a system wherein there are multiple responses. In this system, since it is not possible to maximize every response simultaneously, a compromise or 'trade-off' of some properties becomes necessary. Optimization with constraints is the technique employed for this purpose.

\subsection{Flexural properties}

\subsubsection{Effects of process variables on flexural yield stress}

In this section, effects of process variables on the flexural yield stress of the epoxy/4 wt $\%$ OMMT nanocomposites are discussed. The flexural yield stress values were measured and are given in Table 3. These results were analyzed by employing Design Expert Version 6 Software (Star-Ease Corporation, 2003) to establish the mathematical functional relations as well as a number of statistics to confirm the variables of the models. The experimental data in Table 3 was analyzed. A linear model was found to fit adequately the experimental data. The adequacy of the model was established by ANOVA, Normal Probability plot and Residual Analysis. Through the estimation of all regression coefficients, the experimental response could be modeled as a polynomial equation that shows the effect of experimental factors on the yield stress. The linear function obtained is given in Equation (1):

Flexural yield stress $=$

$+75.88-2.40 \cdot X_{1}+1.78 \cdot X_{2}+2.88 \cdot X_{3}$

With the probability value $p<0.0001$, significant lack of fit $(p=0.0035)$ and reasonable correlation coefficient $\left(R^{2}=0.6068\right)$.

The response function could be represented graphically by perturbation plots and three dimensional (3D) plots. Perturbation graph shows the effect of

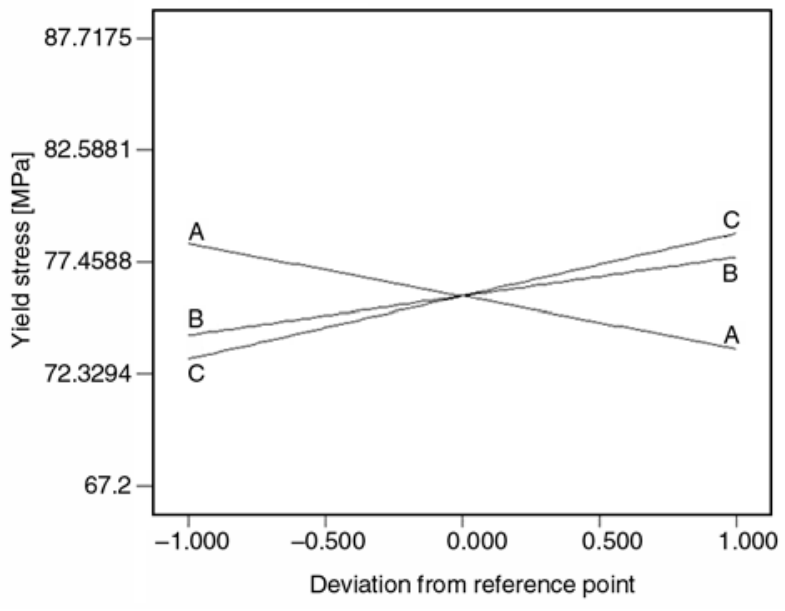

Figure 1. Flexural yield stress of epoxy/4 wt $\%$ OMMT nanocomposites as a response of 3 factors in perturbation plots. A - speed of mechanical stirrer; $\mathrm{B}$ - post curing time; $\mathrm{C}$ - post curing temperature

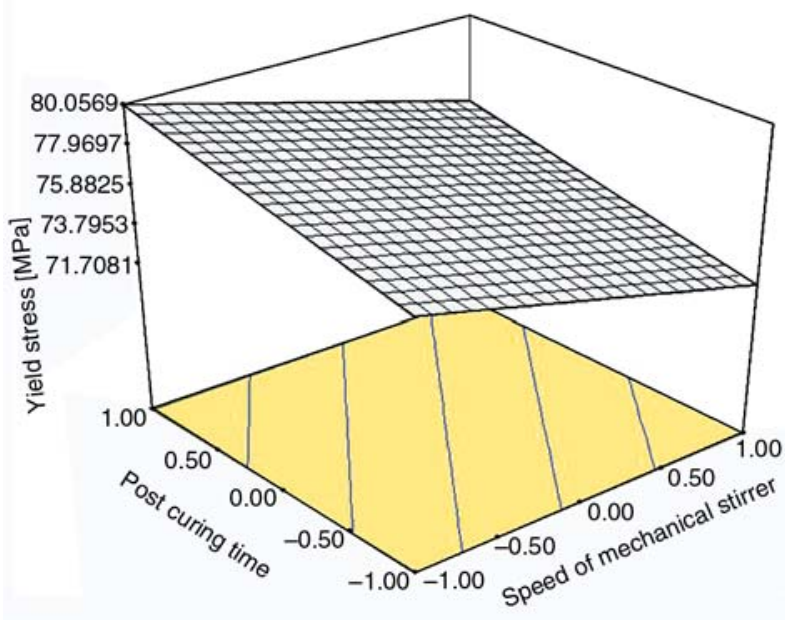

Figure 2. 3D response surface plot of the flexural yield stress as a function of speed of mechanical stirrer and post curing time in coded values

changing one factor while holding the rest as constant. This plot can be useful when trying to decide which axes to use on a contour or 3D plot. Perturbation plot in Figure 1 shows the effect of speed of mechanical stirrer, post curing time and post curing temperature variables on the flexural yield stress of the epoxy/4 wt $\%$ OMMT nanocomposites. Flexural yield stress of the epoxy/4 wt\% OMMT nanocomposites show an increase as the level of post curing time and post curing temperature increased. A slightly reduction in flexural yield stress is observed as the speed of mechanical stirrer increased.

Figure 2 shows the 3D response surface plot of the flexural yield stress as a function of speed of the mechanical stirrer and post curing time in coded 


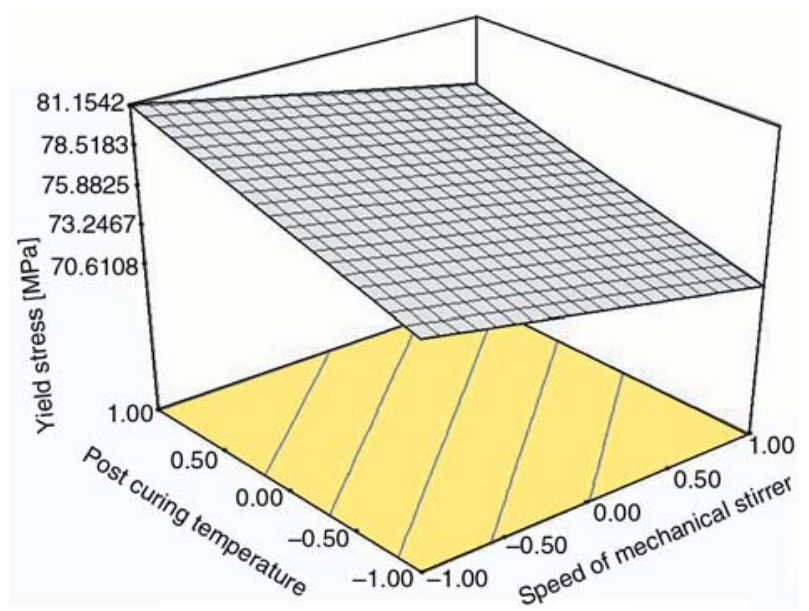

Figure 3. 3D response surface plot of the flexural yield stress as a function of speed of mechanical stirrer and post curing temperature in coded values

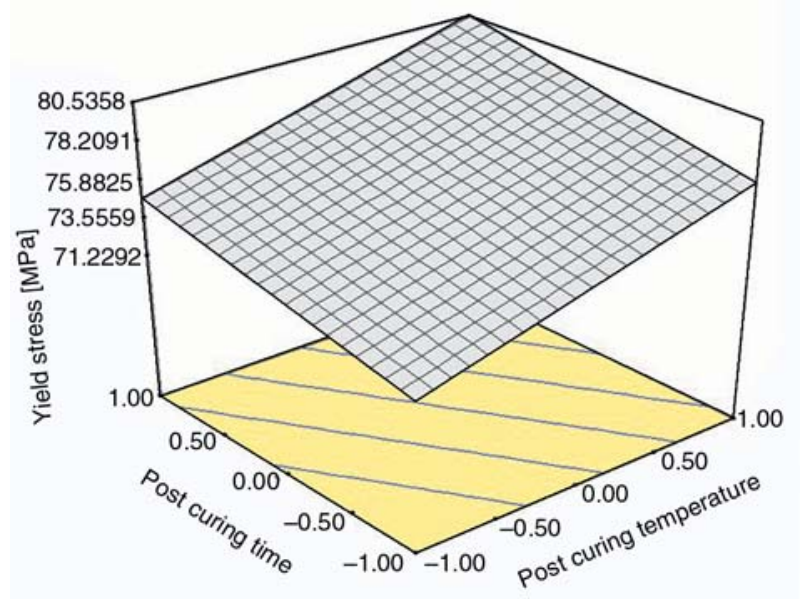

Figure 4. 3D response surface plot of the flexural yield stress as a function of post curing temperature and post curing time in coded values

values. Figure 3 shows that 3D response surface plot of the flexural yield stress as a function of speed of the mechanical stirrer and post curing temperature in coded values. 3D response surface plot of the flexural yield stress as a function of post curing temperature and post curing time in coded values was shown in Figure 4.

Note that all three-dimensional plots show the same trend. From Figure 2, it can be seen that at low level of post curing time, as speed of mechanical stirrer increasesd, the flexural yield stress decreased. However, at high level of post curing time, the flexural yield stress increased as speed of mechanical stirrer decreased. Table 3 shows that as the level of post curing time increases from 36 to 104 minutes, the flexural yield stress increases from 71 to $79 \mathrm{MPa}$. This indicates that the longer the post-curing time, the higher the degree of crosslinking. Similar to what happened in the case of the effect of post curing time towards the flexural yield stress. The effect of post curing temperature showed similar trend as displayed in Figure 3 and Figure 4.

Flexural yield stress of epoxy/OMMT nanocomposites increased as the post curing temperature increase due to the establishment of higher degree of crosslinking. According to Camino et al. [13], curing conditions are of paramount importance to the final properties of the epoxy/OMMT nanocomposites. It is important to select a curing condition that could achieve a balance between intragallery and extragallery polymerization rates which allow better clay exfoliation. If the curing time and curing temperature is too low and the rates of epoxy and crosslinker intercalation are slow, then extragallery polymerization is faster than the intragallery polymerization and hence the poor interaction between filler and matrix could result. On the other hand, the higher curing temperature and higher curing time will promote a higher degree of crosslinking. Tolle and Anderson [14] have reported that the curing of thermosetting resins involves the interaction and chemical kinetics; therefore the physical and mechanical properties will be changed.

Figures 2 and 3 show that the flexural yield stress decreased as the speed of mechanical stirrer increased. The two of three-dimensional plots shows the same trends. From Table 3, it is shown that the flexural yield stress decreases from 78 to $73 \mathrm{MPa}$ when the speed of mechanical stirrer increases from 528 to $1873 \mathrm{rpm}$. This may due to the bubbles that were easily created and trapped inside the sluggish mixture when the speed of mechanical stirrer is relatively high. If the speed of mechanical stirrer too high, the mixing process introduces air into the formulation and the microvoid may exist in the epoxy/OMMT nanocomposites samples. According to Akbari and Begheri [15], the reduction of flexural yield stress was attributed to the formation of micro-void in the nanocomposites system. It was claimed that microvoids act as stress concentrators and facilitate shear yielding in the nanocomposites system and therefore reduce the flexural yield stress. 


\subsubsection{Effects of process variables on flexural modulus}

The values of flexural modulus of epoxy/OMMT nanocomposites prepared in this study are given in Table 3. All the experimental data were collected and analyzed. The results of the CCD experiments on the effect of the process variables in flexural modulus are tabulated in Table 3 and presented in Figures 5-8.

The experimental data in Table 3 were analyzed. From these results, suitable model was selected. The adequacy of the model was established by ANOVA, Normal Probability plot and Residual Analysis. Through the estimation of all regression coefficients, the experimental response can be modeled as a polynomial equation that shows the effect of process variables on the flexural modulus of epoxy/OMMT nanocomposites. The linear function obtained is given in Equation (2):

Flexural modulus $=$ $+2912.91-49.33 \cdot X_{1}-65.13 \cdot X_{2}+135.47 \cdot X_{3}$

With the probabilty value $p>0.0112$, significant lack of fit $(p=0.0258)$ and reasonable correlation coefficient $(R=0.4902)$.

The response function could be represented graphically by perturbation plots and three dimensional plots (3D). The perturbation plot in Figure 5 shows that the post-curing time and post curing temperature were responsible to increase the flexural modulus during the preparation process. However, the

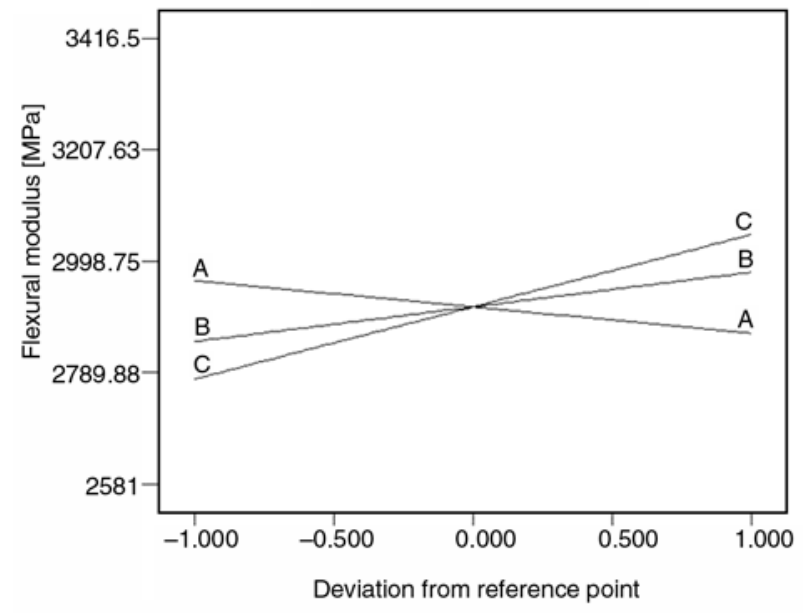

Figure 5. Flexural modulus of epoxy/OMMT nanocomposites as a response of 3 factors in perturbation plots. A - speed of mechanical stirrer; B - post curing time; $\mathrm{C}$ - post curing temperature speed of mechanical stirrer was responsible to decrease the flexural modulus as the speed of mechanical stirrer increased. From Table 3, the highest flexural modulus $3259 \mathrm{MPa}$ can be obtained by employing combination of speed of mechanical stirrer with $1200 \mathrm{rpm}$, post-curing time 100 minutes and post-curing temperature $100^{\circ} \mathrm{C}$ for the preparation of epoxy/OMMT nanocomposites. When Figure 1 and 5 are compared, it can be seen that the same trend can be observed. This indicates that an increasing of post curing time and post curing temperature resulted in increasing flexural modulus. However, increasing the speed of mechanical stirrer will decrease the flexural modulus.

The effects of post curing time and speed of mechanical stirrer on flexural modulus of epoxy/

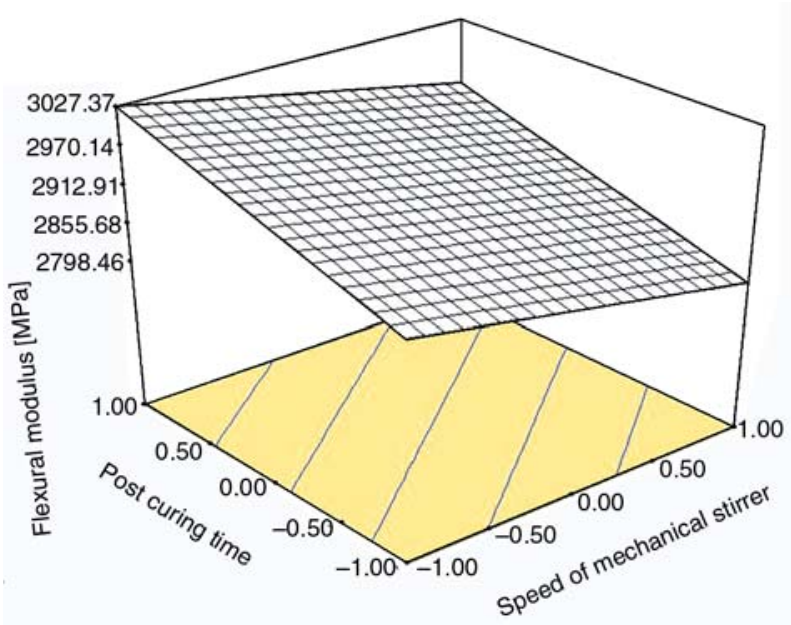

Figure 6. 3D response surface plot of flexural modulus as a function of speed of mechanical stirrer and post curing time in coded values

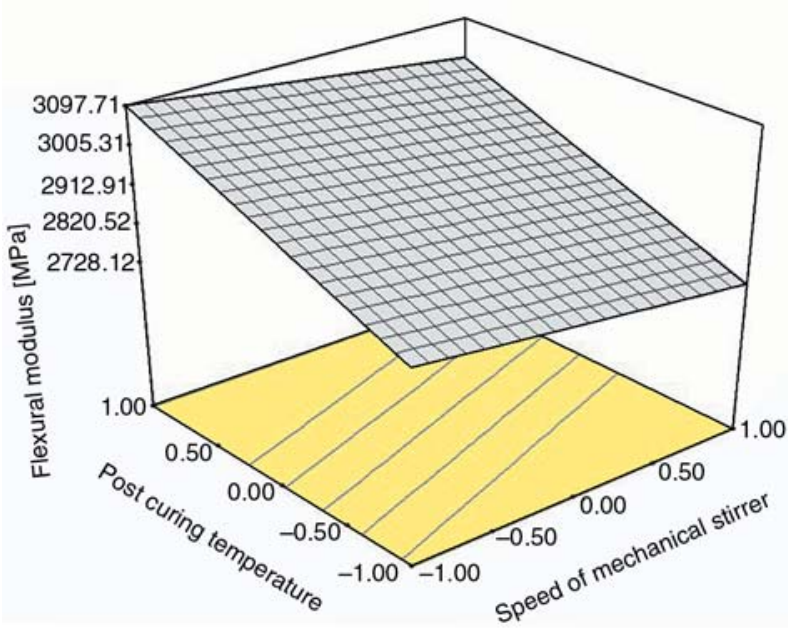

Figure 7. 3D response surface plot of flexural modulus as a function of speed of mechanical stirrer and post curing temperature in coded values 
OMMT nanocomposites is shown as 3D curve in Figure 6. Figure 7 shows the 3D response surface plot of flexural modulus as a function of speed of mechanical stirrer and post curing temperature in coded values. It is obvious that the flexural modulus decreased as the speed of mechanical stirrer increased. This may be due to the very high inertial forces in the speed of mechanical stirrer and caused the clay layers to break rather than separate. Once established the inertial forces will cause the heavier sediments to sink to the bottom while keeping the lighter particles at the top. The aim is to use this force to break up the clumps of clay in a polymer solution and separate some of the clay layers as well [16]. According to Saber-Samandari et al. [16] the decrease in the modulus comes from the fact that at high speeds, the large inertial force no longer acts to separate clay layers but also break some of the layers as well making them no longer effective as a good reinforcing filler to improve the polymer properties.

It was observed from the 3D plot in Figure 8 that the flexural modulus increased as the post-curing time and post curing temperature increased. This is again attributed to the higher degree of crosslinking formation as the post-curing time and the post-curing temperature increased as explained earlier. According to Dean et al. [17], at a higher temperature, the combination of a lower prepolymer viscosity and faster intergallery curing are sufficient to yield more significant expansion of the layers. Therefore, the flexural modulus increased as the post curing time and post curing temperature

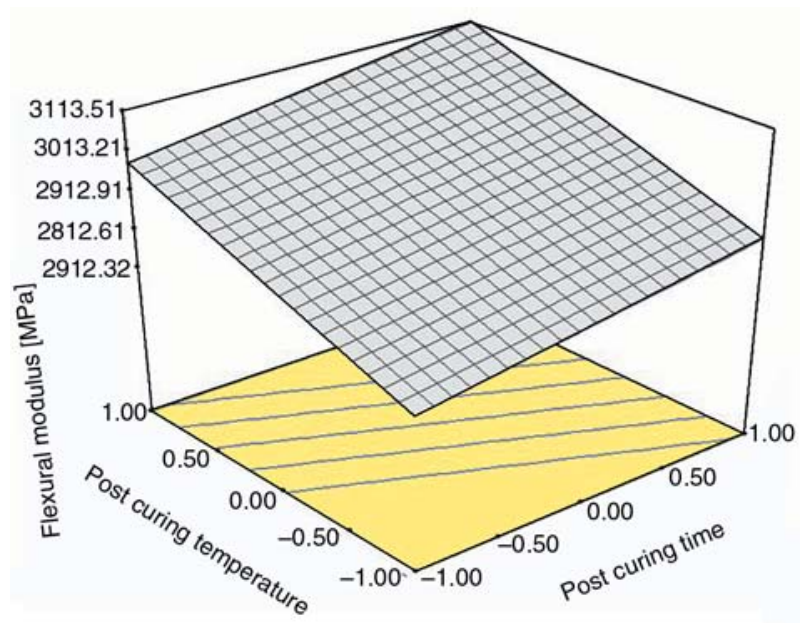

Figure 8. 3D response surface plot of flexural modulus as a function of post curing time and post curing temperature in coded values increased. Kornmann et al. [18] have reported that the highest curing temperature increases the reactivity of the epoxy systems, it also increases the diffusion rate of the epoxy and the curing agent between the layers, favoring the intragallery cure kinetics. This leads to exfoliation of the clay. Due to the reinforcing effects of the clay, strong interaction between the polymer and clay leads to a layer of polymer that is directly adsorbed and bound to the particles. Therefore, it could subsequently improve the flexural modulus. However, if the post curing time is too low and the crosslinker may not have enough time to diffuse into clay galleries, weak interaction between the polymer and clay could result. Consequently, the improvement of flexural modulus may not be achieved.

\subsection{Optimization}

In a multiple response system, since it is not possible to maximize all the response simultaneously, a compromise or 'trade off' of some of the properties is required to be adopted. This type of "optimization with constraint' was adopted in this research. The Design Expert Software has the capability to analyze the results in order to achieve this objective. Numerical optimization was used to optimize any combination of one or more goals. The goals may be apply either factors or responses. In the optimization parameters, the program uses five possibilities for a goal to construct desirability indices, i. e. maximize, minimize, target, within range, none (for responses only). A weight was assigned to the goal to adjust the shape of its particular desirability function. The default value of one creates a linear ramp function between the low value and the goal or the high value and the goal.

Table 5. Criteria for epoxy/4 wt \% OMMT nanocomposites system's responses

\begin{tabular}{|l|c|c|}
\hline \multicolumn{1}{|c|}{ Responses } & Minimum value & Maximum value \\
\hline Flexural yield stress & $67.2 \mathrm{MPa}$ & $87.7 \mathrm{MPa}$ \\
\hline Flexural modulus & $2581 \mathrm{MPa}$ & $3416 \mathrm{MPa}$ \\
\hline
\end{tabular}

Table 6. Constraints applied for optimization

\begin{tabular}{|l|l|}
\hline \multicolumn{1}{|c|}{ Name } & \multicolumn{1}{c|}{ Goal } \\
\hline Speed of mechanical stirrer $[\mathrm{rpm}]$ & is the range \\
\hline Post curing time [minutes] & is the range \\
\hline Post curing temperature $\left[{ }^{\circ} \mathrm{C}\right]$ & is the range \\
\hline Flexural yield stress $[\mathrm{MPa}]$ & in maximum \\
\hline Flexural modulus $[\mathrm{MPa}]$ & in maximum \\
\hline
\end{tabular}


Table 7. Suitable combination of optimization on flexural properties of epoxy/4 wt $\%$ OMMT nanocomposites

\begin{tabular}{|c|c|c|c|c|c|c|}
\hline Number & $\begin{array}{c}\text { Speed of } \\
\text { mechanical stirrer }\end{array}$ & $\begin{array}{c}\text { Post curing } \\
\text { time }\end{array}$ & $\begin{array}{c}\text { Post curing } \\
\text { temperature }\end{array}$ & $\begin{array}{c}\text { Flexural } \\
\text { yield stress }\end{array}$ & $\begin{array}{c}\text { Flexural } \\
\text { modulus }\end{array}$ & Desirability \\
\hline 1 & 800.00 & 90.00 & 119.99 & 82.93 & 3162.73 & 0.731 \\
\hline 2 & 804.34 & 90.00 & 120.00 & 82.91 & 3162.30 & 0.730 \\
\hline 3 & 812.08 & 89.98 & 120.00 & 82.86 & 3161.29 & 0.728 \\
\hline 4 & 800.01 & 90.00 & 119.64 & 82.83 & 3157.94 & 0.725 \\
\hline 5 & 800.00 & 90.00 & 118.54 & 82.51 & 3143.02 & 0.709 \\
\hline 6 & 800.00 & 90.00 & 117.40 & 82.19 & 3127.62 & 0.691 \\
\hline
\end{tabular}

Determinations of final product's criteria are the first step in the optimization process. Determinations of criteria depend on mechanical properties of end product required from the research. Numerical method and graphical method in Design Expert can be used in optimization process. All the criteria for every desirable response are listed in Table 5. Design Expert has been used to determine the combination of variables that give the optimum response based on the desirable criteria. The constraints in this study were chosen as to minimize all the process variables to achieve overall economy of the process. The goals were set to maximize, minimize, target, within range or none as shown in Table 6.

By using Design Expert software in optimization process, all solutions or combinations of optimum responses for process variables of epoxy/4 wt $\%$ OMMT nanocomposites is shown in Table 7. Table 7 shows all the predicted values for each of the response and operating variables combinations. First combination was chosen because it has the highest desirability. Desirabilities range from zero to one for any given response. The program combines the individual desirabilities into a single number and then searches for the greatest overall desirability. A value of one represents the ideal case while a zero indicates that one or more response fall outside desirable limits. In the future work, investigation will be performed on this combination of optimization process parameter for the epoxy/OMMT nanocomposites.

\section{Conclusions}

Statistically designed experiments were conducted and the parameters which influence the flexural properties were established. In term of flexural yield stress, results shows that as the level of post curing time increase from 36 to 104 minutes, the yield stress was increased from 71 to $79 \mathrm{MPa}$. This indicates that the longer the post-curing time, the degree of crosslinking will be higher. Besides, flexural yield stress of epoxy/OMMT nanocomposites increased as the effect of post curing temperature increase due to the formation of higher degree of crosslinking. However, the flexural yield stress decrease from 78 to $73 \mathrm{MPa}$ when the speed of mechanical stirrer increase from 528 to $1873 \mathrm{rpm}$. In term of flexural modulus, the process variables; i. e., post-curing time and post curing temperature were responsible to increase the flexural modulus. However, the speed of mechanical stirrer was responsible to decrease the flexural modulus as the speed of mechanical stirrer increase. Optimization processes have been carried out to determine the suitable combinations of operating variables in order to attain desirable flexural properties.

\section{Acknowledgements}

W. S. Chow would like to thank Universiti Sains Malaysia and Ministry of Higher Education Malaysia for the research grant support and Fundamental Research Grant Scheme (FRGS).

\section{References}

[1] Tarleja R., Manson J. E.: Comprehensive composite materials, Vol 2: Polymer matrix composites. Elsevier Science, Oxford (2000).

[2] Isik I., Yilmazer U., Bayram G.: Impact modified epoxy/montmorillonite nanocomposites: Synthesis and characterization. Polymer, 44, 6371-6377 (2003).

[3] Gu A., Liang G.: Thermal degradation behaviour and kinetic analysis of epoxy/montmorillonite nanocomposites. Polymer Degradation and Stability, 80, 383 391 (2003).

[4] Ho M-W., Lam C-K., Lau K-T., Ng D. H. L., Hui D.: Mechanical properties of epoxy-based composites using nanoclays. Composite Structure, 75, 415-421 (2006). 
[5] Koo J. H.: Polymer nanocomposites: Processing, characterization, and applications. McGraw-Hill, Colombus (2006).

[6] Beyer G.: Nanaocomposites: a new class of flame retardants for polymer. Plastic, Additives and Compounding, 4, 22-28 (2002).

[7] Chen D., He P.: Monitoring the curing process of epoxy resin nanocomposites based on organo-montmorillonite- a new application of resin curemeter. Composites Science and Technology, 64, 2501-2507 (2004).

[8] Montgomery D. C.: Response surface methodology. in 'Design and analysis of experiments' (eds.: Montgomery D. C.) John Wiley and Sons, New York (2001).

[9] Yang K., El-Haik B. S.: Design for six sigma: A roadmap for product development. McGraw-Hill, New York (2003).

[10] Anderson M. J., Kraber S. L.: Eight keys to successful DOE. Quality Digest Magazine, http://www.qualitydigest.com/july99/html/doe.html (1999).

[11] Anderson M.: Design of Experiments. The Industrial Physicist, 3, 24-26 (1997).

[12] Kumar R. N., Woo C. K., Abu Bakar A.: UV radiation curing of surface coatings based on enr cycloaliphatic diepoxide-glycidyl methacrylate system by cationic photoinitiators -Optimization of process variables through response surface methodology. Journal of Coating Technology, 71, 79-88 (1999).
[13] Camino G., Tartaglione G., Frache A., Manferti C., Costa G.: Thermal and combustion behaviour of layered silicate-epoxy nanocomposites. Polymer Degradation and Stability, 90, 354-362 (2005).

[14] Tolle T. B., Anderson D. P.: Morphology development in layered silicate thermoset nanocomposites. Composites Science and Technology, 62, 1033-1041 (2002).

[15] Akbari B., Bagheri R.: Deformation mechanism of epoxy/clay nanocomposites. European Polymer Journal, 43, 782-788 (2007).

[16] Saber-Samandari S., Khatibi A. A., Basic D.: An experimental study on clay/epoxy nanocomposites produced in a centrifuge. Composites, Part B: Engineering, 38, 102-107 (2007).

[17] Dean D., Walker R., Theodore M., Hampton E., Nyairo E.: Chemorhelogy and properties of epoxy/ layered silicate nanocomposites. Polymer, 46, 3014 3021 (2005).

[18] Kornmann X., Lindberg H., Berglund L. A.: Synthesis of epoxy-clay nanocomposites influence of the nature of the curing agent and structure. Polymer, 42, 4493 4499 (2001). 